\title{
A Practical Approach to Nutrition, Protein-Energy Wasting, Sarcopenia, and Cachexia in Patients with Chronic Kidney Disease
}

\author{
Ramy M. Hanna ${ }^{a, b}$ Lena Ghobryc Olivia Wassef $^{d}$ Connie M. Rhee ${ }^{a, b, d}$ \\ Kamyar Kalantar-Zadeha, b, d \\ ${ }^{a}$ Division of Nephrology and Hypertension and Kidney Transplantation, Orange, CA, USA; ${ }^{b}$ Harold Simmons Center \\ for Kidney Disease Research and Epidemiology, University of California Irvine School of Medicine, Orange, CA, \\ USA; ' Department of Medicine, University of Pittsburgh School of Public Health, Pittsburgh, PA, USA; ${ }^{d}$ Division of \\ Nephrology, Department of Medicine, University of California Los Angeles, Los Angeles, CA, USA
}

\section{Keywords}

Protein-energy wasting $\cdot$ Cachexia $\cdot$ Sarcopenia $\cdot$ KALANTAR score $\cdot$ Chronic kidney disease $\cdot$ End-stage renal disease

\begin{abstract}
Objectives of Review: Protein-energy wasting (PEW) is a state of disordered catabolism resulting from metabolic and nutritional derangements in chronic disease states. Patients with chronic kidney disease (CKD), and end-stage renal disease (ESRD) in particular, have muscle wasting, sarcopenia, and cachexia that contribute to frailty and morbidity. Moreover, reverse epidemiology findings have strongly linked PEW with mortality in CKD and ESRD. Updated Findings: The malnutrition-inflammation score (KALANTAR Score) provides a useful tool to predict nutritional risk. A stronger focus on renal nutrition in renal patients is needed to attenuate cachexia and muscle loss. Malnutrition is a far greater threat in patients with renal disease than obesity, which means dietary counseling needs to be tailored to reflect this observation. The need to achieve optimal caloric intake is compounded by the need to limit excess protein intake in CKD, resulting in the need for energy supplementation to avoid PEW. Preventing $\mathrm{PEW}$ is the most pressing clinical concern in CKD/ESRD. Other nutritional issues to reckon in renal disease include the need
\end{abstract}

to normalize serum bicarbonate to manage acidosis, uric acid control, and phosphorous control in CKD and ESRD. Exercise maybe beneficial, but further work is needed to prove a conclusive benefit via a randomized trial. Summary: PEW prevention is an integral part of renal nutrition and is of paramount importance given the obesity paradox. Integrative approaches by physicians and dieticians are needed to take a holistic view of a patient's diet beyond just control of particular laboratory parameters.

C 2019 S. Karger AG, Basel

\section{Introduction}

Protein-energy wasting (PEW) was historically first introduced in 2007 by the International Society of Renal Nutrition and Metabolism [1,2]. The definition codified was that PEW is a state of nutritional and metabolic derangements in patients with chronic kidney disease (CKD) and end-stage renal disease (ESRD) characterized by simultaneous loss of systemic body protein and energy stores. The reason this occurs is related to the hypercatabolic state induced by uremia, anorexia due to poor appetite, inflammation from systemic conditions (Diabetes), and auto immune conditions that generally lead to

\section{KARGER}

(c) 2019 S. Karger AG, Basel

E-Mail karger@karger.com

www.karger.com/bpu
Kamyar Kalantar-Zadeh

Division of Nephrology and Hypertension and Kidney Transplantation

University of California Irvine School of Medicine

101 The City Drive South, Orange, CA 92868 (USA)

E-Mail kkz@uci.edu 
Table 1. Clinical criteria for PEW diagnosis in CKD

Serum chemistry

Serum albumin $<3.8 \mathrm{~g} / \mathrm{dL}$, transthyretin (pre-albumin) $<30 \mathrm{mg} / \mathrm{dL}$ (in dialysis patients)

$B M I$

$<23 \mathrm{~kg} / \mathrm{m}^{2}$

$5 \%$ weight loss over 3 months or $10 \%$ over 6 months

Total body fat percentage $<10 \%$

Muscle mass loss

$5 \%$ reduction in muscle mass over 3 months or $10 \%$ over 6 months

Reduced mid arm muscle circumference by $10 \%$ in relation to 50 th percentile

Lower than expected serum creatinine

Deficient dietary intake

$<0.8 \mathrm{~g} / \mathrm{kg} /$ day of protein for at least 2 months in dialysis patients

$<25 \mathrm{kcal} / \mathrm{kg} /$ day for at least 2 months

PEW, protein-energy wasting; CKD, chronic kidney disease; BMI, body mass index.

CKD and ESRD [2]. The evidence tends to suggest that this develops more in patients with CKD stage $3 \mathrm{~b}$ (estimated glomerular filtration rate $<45 \mathrm{~mL} / \mathrm{min}$ ) as defined by the Kidney Disease Improving Global Outcomes staging of CKD. While PEW and malnutrition can result in a similar patient phenotype, they should be distinguished from one another given the CKD-related factors are unique to the development of PEW in patients with renal disease. See Table 1 for diagnostic criteria for PEW.

This physiologically leads to cachexia, fat loss, and lean muscle mass loss $[1,2]$. Further studies have revealed an alarmingly high rate of PEW in CKD, ESRD, and even acute kidney injury (AKI) patients [3]. Carrero et al. [3] revealed that studies among AKI patients showed 60$82 \%$ PEW prevalence, CKD 3-5 patients showed $11-54 \%$ PEW prevalence, and studies of transplant patients showed 28-52\% PEW prevalence. Figure 1 demonstrates the relationship between Kidney Disease Improving Global Outcome staging of CKD and contribution of relative factors to nutritional dysfunction.

Etiologically, the unique mechanisms of PEW in CKD were described in Carrero et al. [4] 2014 [5]. These include uremia-induced alterations resulting in increased energy expenditure, persistent inflammation, acidosis, and multiple endocrine disorders. The hyper catabolism of muscle and fat combined with decreased nutritional intake, inflammation, nutrient loss, poor physical activity, frailty, and the dialysis procedure per se further contribute to PEW. See Figure 2 for a more precise etiological map of the causal factors of PEW in CKD and ESRD patients. In dialysis patients, slowing down or preventing
PEW remains a challenge. The cornerstone of therapy is nutritional supplementation, optimization of dialysis regimen, management of volume overload, and management of endocrine disorders [6]. Our objective in this review is to define the diagnosis of PEW and connect it with its consequences and relationship with reverse epidemiology, muscle wasting, frailty, and ultimately morbidity and mortality outcomes. We aim to discuss nutritional assessment tools in CKD and ESRD, the state of the art in dietary counseling in renal patients, as well as practical therapeutic interventions to limit the effects of PEW on patients suffering from renal disease.

\section{PEW and Clinical Outcomes in CKD}

Studies have shown that patients who develop ESRD and started on hemodialysis treatment are prone to progressive decline in nutritional parameters [7]. Weight, body mass index, and fat mass tend to decrease, while proinflammatory cytokine markers such as C-reactive protein and interleukin 6 (IL-6) increase progressively over time [8]. As albumin is negatively affected by inflammation as an acute phase marker (inversely related to inflammation), it unsurprisingly tends to decrease with a heightened proinflammatory state [9]. This phenomenon has been observed to increase with time on dialysis (previously titled dialysis vintage). The above factors are directly proportional to weakness, frailty, decreased response to erythropoiesis-stimulating agents, and low quality of life scores by patient self-assessment. More om- 


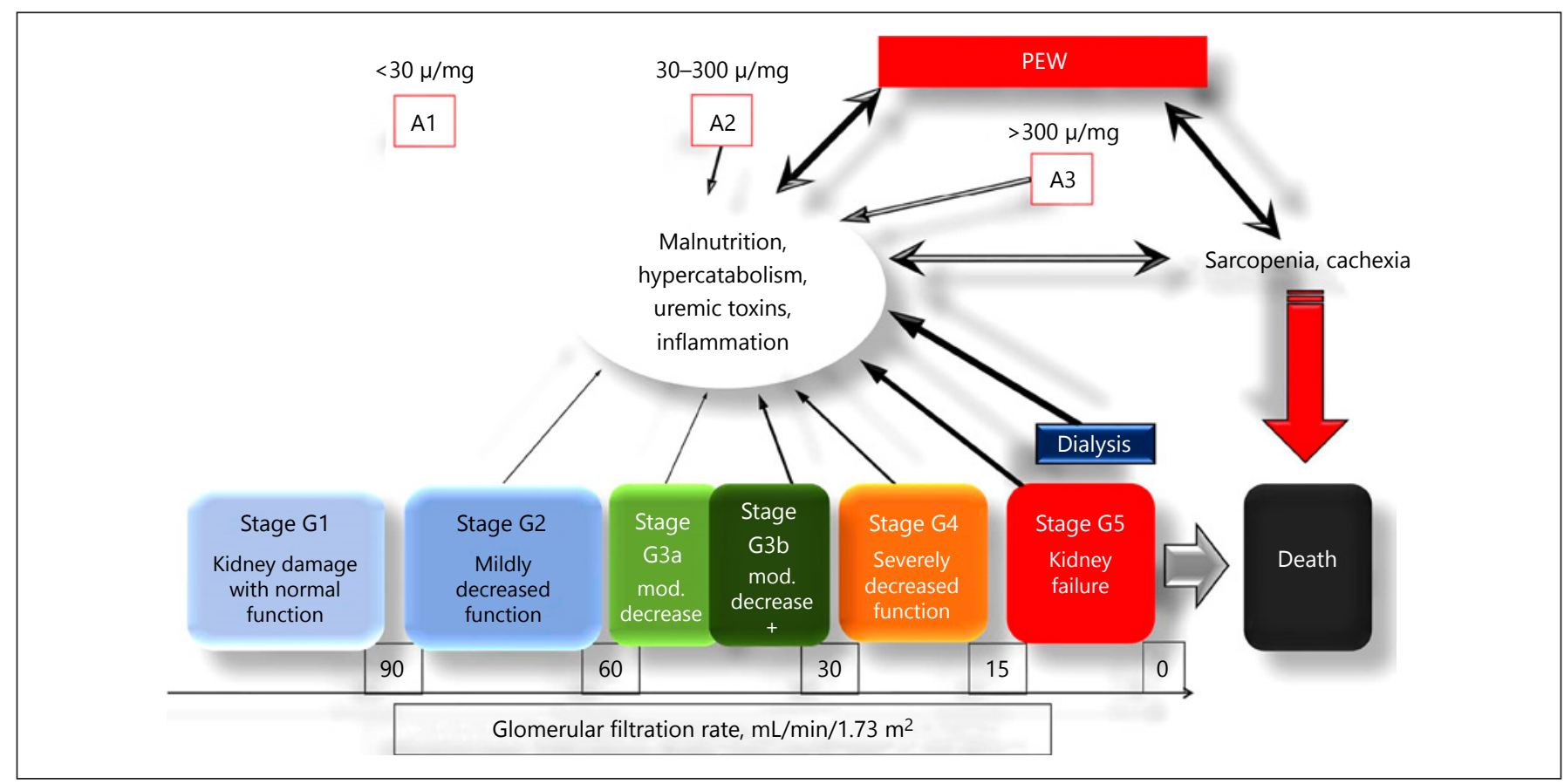

Fig. 1. Conceptual model of PEW and relative contribution of $\mathrm{CKD}$ to various physiological factors as renal disease progresses. A, proteinuria KDIGO stage; G, KDIGO glomerular filtration stage; mod., moderate; (G3b is associated with more advanced CKD than G3a hence it is labeled as mod.+). KDIGO, kidney disease improving global outcome; PEW, protein-energy wasting.
Fig. 2. Interaction of pathological factors that produces a PEW state in CKD. CKDrelated factors that reinforce the deterioration of nutritional status and overall health. PEW, protein-energy wasting.

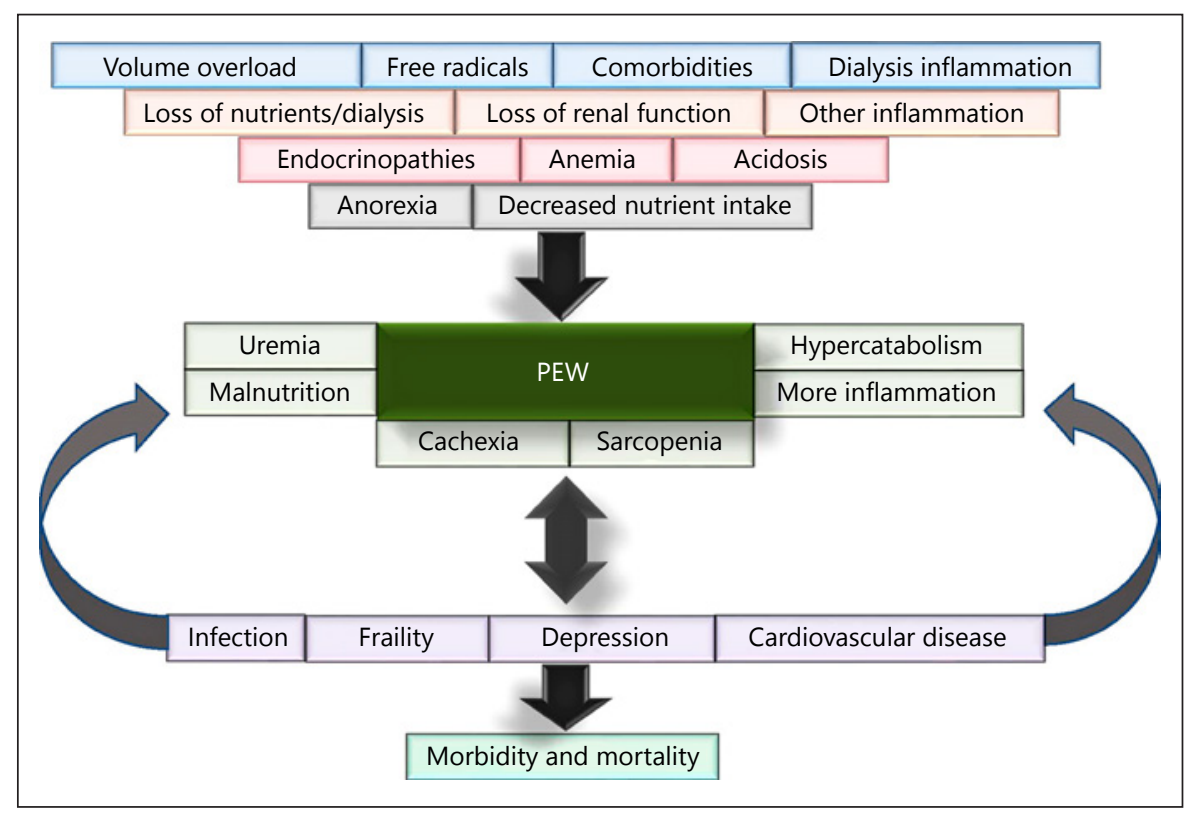

\section{Methods used in the Assessment of PEW}

inously, the changes of PEW due to inflammation also correspond to increased hospitalization and mortality [7-11]. Hypoalbuminemia remains one of the most potent risk factors for excess mortality in hemodialysis patients $[10,11]$.

Besides the diagnostic criteria for PEW (body mass index, muscle mass loss, and deficient dietary intake), see Table 1, dedicated scoring systems have been developed 
Table 2. Data collected for the SGA and MIS

SGA

Nutrient intake, weight change, symptoms (abdominal pain, dental pain, anorexia, early satiety, nausea, vomiting, constipation, dysphagia, diarrhea). Functional capacity, metabolic requirements, physical exam findings. These go into calculating final SGA rating

MIS/KALANTAR score

Change in dry weight, dietary intake, gastrointestinal symptoms, functional capacity, comorbidity, change in fat stores, signs of muscle wasting, BMI $\left(\mathrm{kg} / \mathrm{m}^{2}\right)$, serum albumin $(\mathrm{g} / \mathrm{L})$, serum total iron-binding capacity $(\mathrm{mg} / \mathrm{dL})$. Scored $0-3$ ( 0 not present, 3 is severe)

GNRI

Serum albumin $(\mathrm{g} / \mathrm{L})$, actual-to-ideal body weight ratio

SGA, subjective global assessment; MIS, malnutrition inflammation score; GNRI, geriatric nutritional risk index; BMI, body mass index.

to aid in assessing nutritional status. The measures of nutritional risk in turn correlate with the aforementioned poor outcomes and attendant higher risks of morbidity, hospitalization, frailty, and mortality [12-14]. The 2 scoring systems available are the Subjective Global Assessment and the KALANTAR score also known as the Malnutrition Inflammation Score (MIS). Table 2 contains the data collected in the SGA and the MIS/KALANTAR score $[15,16]$. Moreover, the data track outcomes in patients with AKI and renal transplants, not just in patients with CKD and ESRD [12-16]. The MIS/KALANTAR score has also been associated with elevated IL-6 levels, providing a possible link to the observed increase in morbidity and mortality risk [12-16]. Recently a "simple objective nutritional tool" was developed for assessing PEW and nutritional risk in geriatric patients [2]. The geriatric nutritional risk index utilizes only serum albumin and actual/ideal body ratio. It was validated in Asian ESRD patients and had a higher interobserver agreement in prevalent hemodialysis patients than the MIS [12, 17-20]. Despite agreement of both scores with markers of iron metabolism (transferrin), lipid metabolism (cholesterol), muscle metabolism (creatinine), and cytokines (IL-6), the MIS was superior with regard to predicting death and associations with changes in daily energy and protein intake.

\section{The Reverse Epidemiology of Obesity and Hyperlipidemia in CKD}

A key tenant to understanding the pathophysiology of increased mortality in patients with renal disease is the observation of the obesity paradox. The finding that obesity is protective in CKD and ESRD was unexpected given the deleterious role it played in classical epidemiological cohorts. Consistently, it has been noted that regardless of sex, age, and the severity of obesity, obesity has an unexpected protective effect in CKD and ESRD patients. While surprising at first glance, the effects of reduced renal clearance of waste and solutes, disordered IL signaling, dysregulation of endocrine pathways, and electrolyte homeostasis may well ultimately explain these observations. The finding that hyperlipidemia and obesity are protective again bears witness to the fact that the usual epidemiological rules do not apply in renal patients [21,22]. Rather what is at play is the powerful effect of malnutrition and PEW as a primary determinant of patient morbidity and mortality in CKD and transplant listed ESRD patients [23,24]. It is also quite possible that disorders of electrolyte homeostasis, particularly hyperphosphatemia and elevated fibroblast growth factor 23, may have more significant roles in cardiovascular disease in CKD and ESRD than traditional hyperlipidemia parameters [25].

The strength of signal obtained from the protective effect of high BMI was stronger in younger incident US hemodialysis patients ( $<65$ years old) [26], and this was different than a U-shaped association reported in a similar population in the Netherlands [27]. There did not seem to be any apparent protective effect in incident dialysis patients older than 65 years old [28]. Differences in follow-up have made direct comparisons of the aforementioned studies between older and younger incident dialysis patients difficult $[27,28]$. Further, cohorts enriched for peritoneal dialysis patients tended to show less consistent reverse epidemiology associations [23].

There appears to be a shift in the epidemiological risk factors for morbidity and mortality as patients progress through the stages of CKD and into ESRD. Lu et al. [28] demonstrated that BMI had a U-shaped association with mortality in patients with stage III CKD. The best out- 
comes were in mildly overweight individuals with poor outcomes at the extremes of obesity and cachexia. As patients transition to stage IV CKD and ESRD the classic epidemiology risk factor of obesity disappeared and high BMI became protective [28]. Reverse epidemiology of obesity has also been observed in patients with normal renal function but ongoing proteinuria. In this case, the risk of obesity is modified, and it becomes less deleterious in patients with proteinuria [29].

\section{Frailty}

Frailty is defined by observations of weakness, slow gait, exhaustion, low tolerance for physical activity, unintentional weight loss, and muscle mass to the point of being $<10$ the percentile of age- and sex-matched population controls [2]. If 3 or more of the preceding are true, frailty can be diagnosed. It has a strong relationship with muscle wasting, PEW, and morbidity and mortality in CKD, maintenance dialysis, and even posttransplant [3034 . The prevalence of frailty approaches $30 \%$ of incident hemodialysis patients [35], and this is a progressive change that has been noted to worsen as patients advance through the stages of CKD [36]. Worsening CKD stage and longer dialysis vintage also seemed to correlate with progressive loss of leg skeletal muscle mass as measured by computed tomography scans [37].

While research studies can take advantage of dual energy radiograph absorptiometry and magnetic resonance imaging to measure lean body mass, a 24 -h urine creatinine excretion can be a surrogate for muscle mass. In particular, faster decline in urine creatinine can be an effective surrogate for muscle mass decline [38]. Serum creatinine can also provide an estimate for muscle mass procured diet and residual renal function are accounted for [39, 40]. Park et al. [41] verified that in 2 Korean Cohorts of hemodialysis patients and matched with US Caucasian and African American cohorts a higher BMI and serum creatinine was associated with better survival.

Conversely, it was noted that a decline in serum creatinine correlated with a higher risk of mortality than weight loss. This would make sense as declining serum creatinine would indicate a decrease of lean muscle tissue as described by Kalantar-Zadeh et al. [42, 43]. The result described suggests that mortality is linked with lean muscle mass rather than weight per se. This is likely since edema fluid is part of the component of a great deal of weight fluctuations, and more precise volume management with bioimpedance spectroscopy is not associated with worse outcomes but better outcomes [44]. It is notable that volume overload as estimated by bioimpedance spectroscopy and higher fat mass were also both associated with a higher risk of frailty [35], again this zeroes in on lean muscle mass rather than weight, BMI, or body fat composition as the strongest predictor of frailty risk and risk of poor outcomes in CKD, ESRD, and transplant patients.

\section{Dietary Therapy in Renal Disease}

In light of the above, dietary interventions to preserve lean muscle mass and provide adequate energy supplementation are paramount to the health of dialysis patients. Particularly hemodialysis patients who specifically show one or more surrogate measures concerning for low or decreased lean muscle mass. Dietary protein intake of $0.6-0.8 \mathrm{~g} / \mathrm{kg} /$ day and dietary calorie intakes of $30-$ $35 \mathrm{kcal} / \mathrm{kg} /$ day have been recommended for stage IIIb-V CKD. Despite the risks of negative protein balance, a low protein diet (LPD) is advocated in CKD given the risk of CKD progression with a higher protein diet $[2,6,45,46]$. $\mathrm{Wu}$ et al. [45] suggested that supplementing a LPD improves adherence to this diet has beneficial effects on renal disease in addition to attenuating PEW.

Protein restriction can be used via a LPD with energy supplementation with fat and carbohydrates [45], but it is best used in younger CKD patients as the protective effects of a LPD are less pronounced in the elderly [47]. Thus, protein restriction to limit CKD prevention should be balanced against development of PEW, which would result in worse renal and mortality outcomes [2].

The recommendations for protein intake in ESRD patients reflect the concern for worsening PEW and need to prevent sarcopenia and cachexia that carry such devastating clinical and epidemiological risks. The typical recommendation is $1.2 \mathrm{~g} / \mathrm{kg} /$ day protein intake in ESRD. This is since uremia is no longer a concern and can be cleared by efficient dialysis, but the appearance of declining muscle mass is an acute concern that augurs poorly for incident hemodialysis patients [2, 48-52].

\section{Hyperphosphatemia Management}

Elevated levels of phosphorous have been shown to increase cardiovascular and mortality risks in CKD and ESRD patients [2]. Non calcium-based binders reduce phosphorous and mitigate the risk of vascular calcifications, cardiovascular mortality $[2,53]$. Despite the high 
phosphorous content in animal protein-containing foodstuffs, high phosphorous negates any protective effect of protein and results in increased mortality risk [54-56].

The apparent mechanism is inflammation, and hyperphosphatemia induces dose-dependent oxidative stress independent of level of underlying renal function in animal models as shown by Yamada et al. [57]. In doing so hyperphosphatemia induces PEW, weight loss, hypoalbuminemia, and sarcopenia reflected in reduced urinary creatinine clearance. Though further data in humans on hyperphosphatemia and PEW are needed, proteinuria is not advocated in ESRD patients, but rather phosphorous control to eliminate its unwanted inflammatory sequela. The effect of controlling protein to reduce serum phosphorous has produced results showing that hypoalbuminemia negates the benefits of controlling serum phosphorous. This suggests that dietary protein restriction in ESRD to control phosphorous can inadvertently increase the risk of mortality [58].

\section{Maintenance of Acid Base Homeostasis}

Acidemia is a commonly seen complication of CKD, ESRD, and in transplant patients with CKD. Acidosis can result in systemic symptoms, leukocytosis, disordered breathing, paradoxical hypothermia, and multisystem organ failure acutely [59]. Chronically, a less severe acidosis can result in a reduction of glomerular filtration rate independently of the cause of the acidosis or CKD [60]. An acidotic state can affect PEW by inducing muscle wasting via increases in glucocorticoid secretion [3]. Additionally, acidemia contributes to decreased muscle protein synthesis via decreased albumin synthesis caused by insulin resistance and other endocrine abnormalities [60, 61]. Muscle breakdown also increases via increased branched chain ketoacid dehydrogenase and ATP-dependent ubiquitin proteinase besides glucocorticoid increases $[60,61]$. Other mechanisms increasing the PEW state include generalized inflammation due to acidemia and reductions in serum leptin leading to anorexia $[60,61]$.

Alkalization of serum-to-normal levels $23 \mathrm{meq} / \mathrm{L}$ but not over alkalization results in improved survival and decreased rate of progression of CKD [62-68]. Dialysis patients requiring high bicarbonate dialysate concentration especially if their serum $\mathrm{HCO}_{3}$ remained $<23 \mathrm{meq} / \mathrm{L}$ were also found to have a high mortality risk in the Dialysis Outcomes and Practice Patterns Study. Despite possible confounding by indication as acidemic patients tend to have higher dialysis bicarbonate prescriptions [69].

\section{Exercise}

Given the cascade of inflammatory and nutrient wasting in CKD and ESRD, renal patients often have decreased physical activity levels [70, 71]. The lack of physical activity exacerbates the pathophysiology of PEW directly. Strength training has been studied in dialysis patients and has been noted to induce skeletal muscle hypertrophy, increases muscle strength, and improves health-related quality of life in CKD and ESRD patients $[72,73]$. Further studies are needed to confirm safety and efficacy in CKD, ESRD, and transplant patients. Findings from the transplant literature strongly suggest higher risks in transplanting frail patients [74], however, that suggest that exercise tolerance as a marker of frailty and exercise as a means to reverse frailty should be investigated.

\section{Nutrition on Dialysis}

Recent articles have demonstrated that the hemodialysis procedure is opportunities to improve renal nutrition in ESRD patients. Meals can be provided during hemodialysis as an effective strategy to help reduce the burden of PEW $[3,75]$, given the prevalence of PEW in ESRD. In patients unable to tolerate meals or with ongoing PEW despite oral meal supplementation, intradialytic and intraperitoneal parenteral nutrition can be used with efficacy [76]. Food frequency questionnaires are a simple descriptive tool to identify patients at risk for reduced nutrition intake given socioeconomic, psychological, renal/ dialysis-related reasons, as well as systemic physiological causes [77].

Hemodialysis is often run with zero glucose baths in dialysate and induces a catabolic state similar to fasting with diminished gluconeogenesis [78]. This creates a situation for diabetic patients, or malnourished patients with PEW could be in significant risk of hypoglycemic events. Given known mortality risks of these events in diabetic patients, the concept of dialysis nutrition can have an immediate clinical benefit: reduction of hypoglycemia [78].

To reiterate the most important risk factor to control in dialysis patients is the PEW/inflammation complex, and the triad of nutrient loss, decreased nutritional intake, and breakdown of lean muscle mass [79-81]. This is in addition to the critical role dialysis nutritional counseling plays in control of hyperkalemia and hyperphosphatemia $[75,78]$. We advocate for aggressive nutritional therapy and providing nutritional supplementation to di- 
Table 3. Summary of nutrition recommendations in CKD and ESRD

\section{Protein intake}

- CKD 0.6-0.8 g/kg/day protein restriction

- ESRD $1.2 \mathrm{~g} / \mathrm{kg} /$ day increased protein intake due to PEW, don't restrict protein to control Po4

Weight, obesity, and lean muscle mass

- CKD III obesity behaves as classical risk factor

- CKD IV-V obesity's risks are reduced as malnutrition risks due to PEW increases, reverse epidemiology pattern becomes apparent in studies, particularly in older ( $>65$-year-old) patients

- ESRD PEW is a fearsome risk factor and obesity is protective against mortality in ESRD population

- Transplant patients similar to CKD (depends on estimated glomerular filtration rate)

- Proteinuria obesity is less deleterious risk factor in proteinuric patients than nonproteinuric patients

- Reduced lean muscle mass is most predictive of poor outcomes rather than BMI or weight per se. Anthropometric measures, urine creatinine clearance, and serum creatinine are surrogates of this

- Energy supplementation may reduce risks of PEW

Fluid overload

- CKD and ESRD maintenance of euvolemia associated with better outcomes

Frailty

- Worse outcomes at any stage of CKD, ESRD, peri and posttransplantation

Hyperphosphatemia

- CKD and ESRD use of non-calcium-based binders

- Goal Po4 5.5 and below but avoidance of low Po4

\section{Alkalization}

- CKD maintenance of serum bicarbonate at $23 \mathrm{meq} / \mathrm{L}$ without inducing supraphysiological bicarbonate levels

- ESRD goal is maintenance of normal serum bicarbonate, acidosis with greater dialysate bath associated with greater mortality risk

Exercise

- CKD and ESRD strength training is under study to reverse effects of PEW and frailty

\section{Nutrition on dialysis}

- ESRD supplementing with meals or intra dialytic parenteral nutrition in hemodialysis and intraperitoneal nutrition on PD when oral supplements are not effective

- ESRD eating on dialysis provides a convenient way to supplement nutrition and curb hypoglycemia

Uric acid

- CKD maintenance of normal serum uric acid which slows progression of CKD to ESRD index.

CKD, chronic kidney disease; ESRD, end-stage renal disease; PEW, protein-energy wasting; Po4, phosphorous; BMI, body mass

alysis patients on hemodialysis while they are in center. This prevents losing a convenient opportunity to reverse the PEW pathology actively and control one of the most pressing risks for mortality in hemodialysis patients [46, 79-84].

\section{Uric Acid Control}

Though pertaining more to CKD than ESRD, it should be mentioned that uric acid control in CKD patients has been shown in multiple studies to reduce CKD progression [85]. Uric acid is an end product of protein metabo- lism; therefore, while a balanced approach to protein restriction can be used in early-stage CKD, pharmacological control may be necessary in later stage CKD given rising PEW risks. Please see Table 3 that summarizes the nutritional recommendations for patients with CKD and ESRD.

\section{Conclusions}

We have reviewed the pathophysiology of pertinent nutritional issues across the CKD, ESRD, and transplant CKD spectrum. New developments include nutritional benefits 
of intradialytic meal replacement, scoring systems for PEW, and the emerging field of exercise therapy in CKD and ESRD to combat frailty and reverse the effects of PEW.

\section{Acknowledgment}

None.

\section{Disclosure Statement}

Dr. Ramy M. Hanna is a member of the 2018-2019 Speaker's Bureau and a paid consultant for Alexion Pharmaceuticals for Eculizumab and was part of the FDA advisory board regarding Ravulizumab for Alexion Pharmaceuticals. Ms. Lena Ghobry, Dr. Olivia Wassef, and Dr. Connie M. Rhee have nothing to disclose. Dr. Kamyar Kalantar-Zadeh has received honoraria and/or other support from Abbot, Abbvie, ACL Clinical (Cara Therapeutics), Akebia, Alexion, Amgen, Astra-Zeneca, Aveo, B-Braun, Chugai, Cytokinetics, Daiichi, DaVita, Keryx, Kissei, Novartis, Pfizer, Regulus, Relypsa, Resverlogix, Dr Schaer (Flavis), Sandoz, Sanofi, Shire, Vifor, UpToDate, and ZS Pharma.

\section{Author Contributions}

R.M.H. led writing of manuscript. L.G. contributed to text, editing, and compiling references. O.W. contributed to text, editing, and compiling references. C.M.R. contributed to editing text providing significant scientific input. K.K.-Z. led review of manuscript as senior author and expert on renal nutrition.

\section{Financial Support}

K.K.-Z. is supported by the National Institute on Aging of the National Institutes of Health grant R21-AG047036 and the National Institute of Diabetes, Digestive and Kidney Disease grants R01-DK078106, R01-DK096920, U01-DK102163, and K24DK091419, as well as philanthropist grants from Mr. Harold Simmons and Mr. Louis Chang. C.M.R. is supported by research grants from the National Institutes of Health/National Institutes of Diabetes and Digestive and Kidney Diseases K23-DK 102903; National Kidney Foundation (C.M.R.); American Thyroid Association (C.M.R.); and philanthropist grants from Dr. Joseph Lee (C.M.R.).

\section{References}

1 Foque D, Kalantar-Zadeh K, Kopple J, Cano N, Chauvea P, Cuppari L, et al. A proposed nomenclature and diagnostic criteria for protein-energy wasting in acute and chronic kidney disease. Kidney Int. 2008 Feb;73(4):3918.

2 Obi Y, Qader H, Kovesdy CP, Kalantar-Zadeh $\mathrm{K}$. Latest consensus and update on proteinenergy wasting in chronic kidney disease. Curr Opin Clin Nutr Metab Care. 2015 May; 18(3):254-62.

3 Carrero JJ, Thomas F, Nagy K, Arogundade F, Avesani CM, Chan M, et al. Global Prevalence of Protein-Energy Wasting in Kidney Disease: A Meta-analysis of Contemporary Observational Studies From the International Society of Renal Nutrition and Metabolism. J Ren Nutr. 2018 Nov;28(6):38092.

4 Carrero JJ, Stenvinkel P, Cuppari L, Ikizler TA, Kalantar-Zadeh K, Kaysen G, et al. Etiology of the protein-energy wasting syndrome in chronic kidney disease: a consensus statement from the International Society of Renal Nutrition and Metabolism (ISRNM). J Ren Nutr. 2013 Mar;23(2):77-90.

5 Wang XH, Mitch WE. Mechanisms of muscle wasting in chronic kidney disease. Nat Rev Nephrol. 2014 Sep;10(9):504-16.

6 Ikizler TA, Cano NJ, Franch H, Fouque D, Himmelfarb J, Kalantar-Zadeh K, et al. Prevention and treatment of protein energy wasting in chronic kidney disease patients: a consensus statement by the International Society of Renal Nutrition and Metabolism. Kidney Int. 2013 Dec;84(6):1096-107.

7 Su CT, Yabes J, Pike F, Weiner DE, Beddhu S, Burrowes JD, et al. Changes in anthropometry and mortality in maintenance hemodialysis patients in the HEMO Study. Am J Kidney Dis. 2013 Dec;62(6):1141-50.

8 den Hoedt CH, Bots ML, Grooteman MP, van der Weerd NC, Penne EL, Mazairac AH, et al.; CONTRAST Investigators. Clinical predictors of decline in nutritional parameters over time in ESRD. Clin J Am Soc Nephrol. 2014 Feb;9(2):318-25.

9 Kim Y, Molnar MZ, Rattanasompattikul M, Hatamizadeh P, Benner D, Kopple JD, et al. Relative contributions of inflammation and inadequate protein intake to hypoalbuminemia in patients on maintenance hemodialysis. Int Urol Nephrol. 2013 Feb;45(1):215-27.

10 Amparo FC, Cordeiro AC, Carrero JJ, Cuppari L, Lindholm B, Amodeo C, et al. Malnutrition-inflammation score is associated with handgrip strength in nondialysis-dependent chronic kidney disease patients. J Ren Nutr. 2013 Jul;23(4):283-7.

11 Rattanasompattikul M, Molnar MZ, Zaritsky JJ, Hatamizadeh P, Jing J, Norris KC, et al. Association of malnutrition-inflammation complex and responsiveness to erythropoiesisstimulating agents in long-term hemodialysis patients. Nephrol Dial Transplant. 2013 Jul; 28(7):1936-45.

12 Riella MC. Nutritional evaluation of patients receiving dialysis for the management of pro- tein-energy wasting: what is old and what is new? J Ren Nutr. 2013 May;23(3):195-8.

13 Ujszaszi A, Czira ME, Fornadi K, Novak M, Mucsi I, Molnar MZ. Quality of life and protein-energy wasting in kidney transplant recipients. Int Urol Nephrol. 2012 Aug;44(4): 1257-68.

14 Czira ME, Lindner AV, Szeifert L, Molnar MZ, Fornadi K, Kelemen A, et al. Association between the Malnutrition-Inflammation Score and depressive symptoms in kidney transplanted patients. Gen Hosp Psychiatry. 2011 Mar-Apr;33(2):157-65.

15 Fontes D, Generoso SV, Toulson Davisson Correia MI. Subjective global assessment: a reliable nutritional assessment tool to predict outcomes in critically ill patients. Clin Nutr. 2014 Apr;33(2):291-5.

16 Rambod M, Bross R, Zitterkoph J, Benner D, Pithia J, Colman S, et.al. Association of Malnutrition-Inflammation Score with Quality of Life and Mortality in Hemodialysis Patients: a 5-Year Prospective Cohort Study. Am J Kidney Dis. 2009 Feb;53(2):298-309.

17 Kang SH, Cho KH, Park JW, Yoon KW, Do JY. Geriatric Nutritional Risk Index as a prognostic factor in peritoneal dialysis patients. Perit Dial Int. 2013 Jul-Aug;33(4): 405-10.

18 Jung YS, You G, Shin HS, Rim H. Relationship between Geriatric Nutritional Risk Index and total lymphocyte count and mortality of hemodialysis patients. Hemodial Int. 2014 Jan;18(1):104-12. 
19 Tsai MT, Hu FH, Lien TJ, Chen PJ, Huang TP, Tarng DC. Interaction between geriatric nutritional risk index and decoy receptor 3 predicts mortality in chronic hemodialysis patients. Am J Nephrol. 2014;40(3):191-9.

20 Beberashvili I, Azar A, Sinuani I, Kadoshi H, Shapiro G, Feldman L, et al. Comparison analysis of nutritional scores for serial monitoring of nutritional status in hemodialysis patients. Clin J Am Soc Nephrol. 2013 Mar; 8(3):443-51.

21 Cabezas-Rodriguez I, Carrero JJ, Zoccali C, Qureshi AR, Ketteler M, Floege J, et al. Influence of body mass index on the association of weight changes with mortality in hemodialysis patients. Clin J Am Soc Nephrol. 2013 Oct; 8(10):1725-33.

22 Moradi H, Streja E, Kashyap ML, Vaziri ND, Fonarow GC, Kalantar-Zadeh K. Elevated high-density lipoprotein cholesterol and cardiovascular mortality in maintenance hemodialysis patients. Nephrol Dial Transplant. 2014 Aug;29(8):1554-62.

23 Park J, Ahmadi SF, Streja E, Molnar MZ, Flegal KM, Gillen D, et al. Obesity paradox in end-stage kidney disease patients. Prog Cardiovasc Dis. 2014 Jan-Feb;56(4):415-25.

24 Molnar MZ, Streja E, Kovesdy CP, Bunnapradist S, Sampaio MS, Jing J, et al. Associations of body mass index and weight loss with mortality in transplant-waitlisted maintenance hemodialysis patients. Am J Transplant. 2011 Apr;11(4):725-36.

25 Hruska KA, Mathew S, Lund R, Qui P, Pratt R. Hyperphosphatemia of Chronic Kidney Disease. Kidney Int. 2008;74(2):148-57.

26 Vashistha T, Mehrotra R, Park J, Streja E, Dukkipati R, Nissenson AR, et al. Effect of age and dialysis vintage on obesity paradox in long-term hemodialysis patients. Am J Kidney Dis. 2014 Apr;63(4):612-22.

27 Hoogeveen EK, Halbesma N, Rothman KJ, Stijnen T, van Dijk S, Dekker FW, et al.; Netherlands Cooperative Study on the Adequacy of Dialysis-2 (NECOSAD) Study Group. Obesity and mortality risk among younger dialysis patients. Clin J Am Soc Nephrol. 2012 Feb;7(2):280-8.

28 Lu JL, Kalantar-Zadeh K, Ma JZ, Quarles LD, Kovesdy CP. Association of body mass index with outcomes in patients with CKD. J Am Soc Nephrol. 2014 Sep;25(9):2088-96.

29 Obermayr RP, Temml C, Gutjahr G, Kainz A, Klauser-Braun R, Függer R, et al. Body mass index modifies the risk of cardiovascular death in proteinuric chronic kidney disease. Nephrol Dial Transplant. 2009 Aug;24(8): 2421-8.

30 Walker SR, Gill K, Macdonald K, Komenda P, Rigatto C, Sood MM, et al. Association of frailty and physical function in patients with non-dialysis CKD: a systematic review. BMC Nephrol. 2013 Oct;14(1):228.

31 Kim JC, Kalantar-Zadeh K, Kopple JD. Frailty and protein-energy wasting in elderly patients with end stage kidney disease. J Am Soc Nephrol. 2013 Feb;24(3):337-51.
32 McAdams-DeMarco MA, Law A, Salter ML, Boyarsky B, Gimenez L, Jaar BG, et al. Frailty as a novel predictor of mortality and hospitalization in individuals of all ages undergoing hemodialysis. J Am Geriatr Soc. 2013 Jun; 61(6):896-901.

33 Bao Y, Dalrymple L, Chertow GM, Kaysen GA, Johansen KL. Frailty, dialysis initiation, and mortality in end-stage renal disease. Arch Intern Med. 2012 Jul;172(14):1071-7.

34 Matsuzawa R, Matsunaga A, Wang G, Yamamoto S, Kutsuna T, Ishii A, et al. Relationship between lower extremity muscle strength and all-cause mortality in Japanese patients undergoing dialysis. Phys Ther. 2014 Jul;94(7): 947-56.

35 Johansen KL, Dalrymple LS, Delgado C, Kaysen GA, Kornak J, Grimes B, et al. Association between body composition and frailty among prevalent hemodialysis patients: a US Renal Data System special study. J Am Soc Nephrol. 2014 Feb;25(2):381-9.

36 Reese PP, Cappola AR, Shults J, Townsend RR, Gadegbeku CA, Anderson C, et al.; CRIC Study Investigators. Physical performance and frailty in chronic kidney disease. Am J Nephrol. 2013;38(4):307-15.

37 John SG, Sigrist MK, Taal MW, McIntyre CW. Natural history of skeletal muscle mass changes in chronic kidney disease stage 4 and 5 patients: an observational study. PLoS One. 2013 May;8(5):e65372.

38 Di Micco L, Quinn RR, Ronksley PE, Bellizzi V, Lewin AM, Cianciaruso B, et al.; Alberta Kidney Disease Network (AKDN). Urine creatinine excretion and clinical outcomes in CKD. Clin J Am Soc Nephrol. 2013 Nov; 8(11):1877-83.

39 Patel SS, Molnar MZ, Tayek JA, Ix JH, Noori $\mathrm{N}$, Benner D, et al. Serum creatinine as a marker of muscle mass in chronic kidney disease: results of a cross-sectional study and review of literature. J Cachexia Sarcopenia Muscle. 2013 Mar;4(1):19-29.

40 Canaud B, Granger Vallée A, Molinari N, Chenine L, Leray-Moragues H, Rodriguez A, et al. Creatinine index as a surrogate of lean body mass derived from urea Kt/V, pre-dialysis serum levels and anthropometric characteristics of haemodialysis patients. PLoS One. 2014 Mar;9(3):e93286.

41 Park J, Jin DC, Molnar MZ, Dukkipati R, Kim YL, Jing J, et al. Mortality predictability of body size and muscle mass surrogates in Asian vs white and African American hemodialysis patients. Mayo Clin Proc. 2013 May; 88(5):479-86

42 Kalantar-Zadeh K, Streja E, Kovesdy CP, Oreopoulos A, Noori N, Jing J, et al. The obesity paradox and mortality associated with surrogates of body size and muscle mass in patients receiving hemodialysis. Mayo Clin Proc. 2010 Nov;85(11):991-1001.

43 Kalantar-Zadeh K, Streja E, Molnar MZ, Lukowsky LR, Krishnan M, Kovesdy CP, et al. Mortality prediction by surrogates of body composition: an examination of the obesity paradox in hemodialysis patients using composite ranking score analysis. Am J Epidemiol. 2012 Apr;175(8):793-803.

44 Onofriescu M, Hogas S, Voroneanu L, Apetrii M, Nistor I, Kanbay M, et al. Bioimpedance-guided fluid management in maintenance hemodialysis: a pilot randomized controlled trial. Am J Kidney Dis. 2014 Jul;64(1): 111-8.

45 Wu HL, Sung JM, Kao MD, Wang MC, Tseng CC, Chen ST. Nonprotein calorie supplement improves adherence to low-protein diet and exerts beneficial responses on renal function in chronic kidney disease. J Ren Nutr. 2013l Jul;23(4):271-6.

46 Kovesdy CP, Kopple JD, Kalantar-Zadeh K. Management of protein-energy wasting in non-dialysis-dependent chronic kidney disease: reconciling low protein intake with nutritional therapy. Am J Clin Nutr. 2013 Jun; 97(6):1163-77.

47 Levine ME, Suarez JA, Brandhorst S, Balasubramanian P, Cheng CW, Madia F, et al. Low protein intake is associated with a major reduction in IGF-1, cancer, and overall mortality in the 65 and younger but not older population. Cell Metab. 2014 Mar;19(3): 407-17.

48 Lukowsky LR, Kheifets L, Arah OA, Nissenson AR, Kalantar-Zadeh K. Nutritional predictors of early mortality in incident hemodialysis patients. Int Urol Nephrol. 2014 Jan; 46(1):129-40.

49 Ravel VA, Molnar MZ, Streja E, Kim JC, Victoroff A, Jing J, et al. Low protein nitrogen appearance as a surrogate of low dietary protein intake is associated with higher all-cause mortality in maintenance hemodialysis patients. J Nutr. 2013 Jul;143(7):1084-92.

50 Rattanasompattikul M, Molnar MZ, Lee ML, Dukkipati R, Bross R, Jing J, et al. Anti-Inflammatory and Anti-Oxidative Nutrition in Hypoalbuminemic Dialysis Patients (AIONID) study: results of the pilot-feasibility, double-blind, randomized, placebo-controlled trial. J Cachexia Sarcopenia Muscle. 2013 Dec;4(4):247-57.

51 Cheu C, Pearson J, Dahlerus C, Lantz B, Chowdhury T, Sauer PF, et al. Association between oral nutritional supplementation and clinical outcomes among patients with ESRD. Clin J Am Soc Nephrol. 2013l Jan; 8(1):100-7.

52 Lacson E Jr, Wang W, Zebrowski B, Wingard R, Hakim RM. Outcomes associated with intradialytic oral nutritional supplements in patients undergoing maintenance hemodialysis: a quality improvement report. Am J Kidney Dis. 2012l Oct;60(4):591-600.

53 Palmer SC, Hayen A, Macaskill P, Pellegrini F, Craig JC, Elder GJ, et al. Serum levels of phosphorus, parathyroid hormone, and calcium and risks of death and cardiovascular disease in individuals with chronic kidney disease: a systematic review and meta-analysis. JAMA. 2011 Mar;305(11):111927. 
54 Jamal SA, Vandermeer B, Raggi P, Mendelssohn DC, Chatterley T, Dorgan M, et al. Effect of calcium-based versus non-calcium-based phosphate binders on mortality in patients with chronic kidney disease: an updated systematic review and meta-analysis. Lancet. 2013 Oct;382(9900):1268-77.

55 Streja E, Lau WL, Goldstein L, Sim JJ, Molnar MZ, Nissenson AR, et al. Hyperphosphatemia is a combined function of high serum PTH and high dietary protein intake in dialysis patients. Kidney Int Suppl (2011). 2013 Dec; 3(5):462-8.

56 Lertdumrognluk P, Rhee CM, Park J, Lau WL, Moradi H, Jing J, et.al. Association of serum phosphorous concentration with mortality in elderly and non-elderly hemodialysis patients. J Ren Nutr. 2013 Nov;23(6):411-21.

57 Yamada S, Tokumoto $\mathrm{M}$, Tatsumoto $\mathrm{N}$, Taniguchi M, Noguchi H, Nakano T, et al. Phosphate overload directly induces systemic inflammation and malnutrition as well as vascular calcification in uremia. Am J Physiol Renal Physiol. 2014 Jun;306(12):F141828.

58 Shinaberger CS, Greenland S, Kopple JD, Van Wyck D, Mehrotra R, Kovesdy CP, et al. Is controlling phosphorus by decreasing dietary protein intake beneficial or harmful in persons with chronic kidney disease? Am J Clin Nutr. 2008 Dec;88(6):1511-8.

59 Kalantar-Zadeh K, Uppot RN, Lewandrowski KB. Case records of the Massachusetts General Hospital. Case 23-2013. A 54-year-old woman with abdominal pain, vomiting, and confusion. N Engl J Med. 2013 Jul;369(4): 374-82.

60 Kalantar-Zadeh K, Mehrotra R, Fouque D, Kopple JD. Metabolic acidosis and malnutrition-inflammation complex syndrome in chronic renal failure. Semin Dial. 2004 NovDec;17(6):455-65.

61 Kalantar-Zadeh K, Fouque D. Nutritional Management of Chronic Kidney Disease. N Engl J Med. 2017 Nov;377(18):1765-76.

62 Chen JL, Kalantar-Zadeh K. Is an increased serum bicarbonate concentration during hemodialysis associated with an increased risk of death? Semin Dial. 2014 May-Jun;27(3): $259-62$.

63 Łoniewski I, Wesson DE. Bicarbonate therapy for prevention of chronic kidney disease progression. Kidney Int. 2014 Mar;85(3): 529-35.

64 Kovesdy CP. Metabolic acidosis and kidney disease: does bicarbonate therapy slow the progression of CKD? Nephrol Dial Transplant. 2012 Aug;27(8):3056-62.
65 Dobre M, Yang W, Chen J, Drawz P, Hamm LL, Horwitz E, et al.; CRIC Investigators. Association of serum bicarbonate with risk of renal and cardiovascular outcomes in CKD: a report from the Chronic Renal Insufficiency Cohort (CRIC) study. Am J Kidney Dis. 2013 Oct; 62(4):670-8.

66 Kovesdy CP, Anderson JE, Kalantar-Zadeh K. Association of serum bicarbonate levels with mortality in patients with non-dialysis-dependent CKD. Nephrol Dial Transplant. 2009 Apr;24(4):1232-7.

67 Kidney Disease: Improving Global Outcomes (KDIGO) CKD Work Group. KDIGO 2012 Clinical Practice Guidelines for the Evaluation and Management of Chronic Kidney Disease. Kidney Int Suppl. 2013;3:1-150.

68 Vashistha T, Kalantar-Zadeh K, Molnar MZ, Torlén K, Mehrotra R. Dialysis modality and correction of uremic metabolic acidosis: relationship with all-cause and cause-specific mortality. Clin J Am Soc Nephrol. 2013 Feb; $8(2): 254-64$

69 Tentori F, Karaboyas A, Robinson BM, Morgenstern $\mathrm{H}$, Zhang J, Sen A, et al. Association of dialysate bicarbonate concentration with mortality in the Dialysis Outcomes and Practice Patterns Study (DOPPS). Am J Kidney Dis. 2013 Oct;62(4):738-46.

70 Kim JC, Shapiro BB, Zhang M, Li Y, Porszasz J, Bross R, et al. Daily physical activity and physical function in adult maintenance hemodialysis patients. J Cachexia Sarcopenia Muscle. 2014 Sep;5(3):209-20.

71 Cheema BS, Chan D, Fahey P, Atlantis E. Effect of progressive resistance training on measures of skeletal muscle hypertrophy, muscular strength and health-related quality of life in patients with chronic kidney disease: a systematic review and meta-analysis. Sports Med. 2014 Aug;44(8):1125-38.

72 Kirkman DL, Mullins P, Junglee NA, Kumwenda M, Jibani MM, Macdonald JH. Anabolic exercise in haemodialysis patients: a randomised controlled pilot study. J Cachexia Sarcopenia Muscle. 2014 Sep;5(3):199-207.

73 Watson EL, Kosmadakis GC, Smith AC, Viana JL, Brown JR, Molyneux K, et al. Combined walking exercise and alkali therapy in patients with CKD4-5 regulates intramuscular free amino acid pools and ubiquitin E3 ligase expression. Eur J Appl Physiol. 2013 Aug;113(8):2111-24.

74 Cheng XS, Lentine KL, Koraishy FM, Myers J, Tan JC. Implications of Frailty for Peritransplant Outcomes in Kidney Transplant Recipients. Curr Transplant Rep. 2019 Mar;6(1): $16-25$.
75 Kistler BM, Benner D, Burrowes JD, Campbell KL, Fouque D, Garibotto G, et al. Eating During Hemodialysis Treatment: A Consensus Statement From the International Society of Renal Nutrition and Metabolism. J Ren Nutr. 2018 Jan;28(1):4-12.

76 Kalantar-Zadeh K, Cano NJ, Budde K, Chazot C, Kovesdy CP, Mak RH, et al. Diets and enteral supplements for improving outcomes in chronic kidney disease. Nat Rev Nephrol. 2011 May;7(7):369-84.

77 Kalantar-Zadeh K, Kovesdy CP, Bross R, Benner D, Noori N, Murali SB, et al. Design and development of a dialysis food frequency questionnaire. J Ren Nutr. 2011 May;21(3): $257-62$.

78 Abe M, Kalantar-Zadeh K. Haemodialysisinduced hypoglycaemia and glycaemic disarrays. Nat Rev Nephrol. 2015 May;11(5):30213.

79 Rambod M, Kovesdy CP, Bross R, Kopple JD, Kalantar-Zadeh K. Association of serum prealbumin and its changes over time with clinical outcomes and survival in patients receiving hemodialysis. Am J Clin Nutr. 2008 Dec; 88(6): 1485-94.

80 Wang AY, Kalantar-Zadeh K, Fouque D, Wee PT, Kovesdy CP, Price SR, et al. Precision Medicine for Nutritional Management in End-Stage Kidney Disease and Transition to Dialysis. Semin Nephrol. 2018 Jul;38(4):38396.

81 Cupisti A, Kovesdy CP, D’Alessandro C, Kalantar-Zadeh K. Dietary Approach to Recurrent or Chronic Hyperkalaemia in Patients with Decreased Kidney Function. Nutrients. 2018 Feb;10(3):E261.

82 Kalantar-Zadeh K, Tortorici AR, Chen JL, Kamgar M, Lau WL, Moradi H, et al. Dietary restrictions in dialysis patients: is there anything left to eat? Semin Dial. 2015 Mar-Apr; 28(2):159-68.

83 Kistler B, Benner D, Burgess M, Stasios M, Kalantar-Zadeh K, Wilund KR. To eat or not to eat-international experiences with eating during hemodialysis treatment. J Ren Nutr. 2014 Nov;24(6):349-52.

84 Noori N, Kovesdy CP, Dukkipati R, Kim Y, Duong U, Bross R, et.al. Survival predictability of lean and fat mass in men and women undergoing maintenance hemodialysis. Am J Clin Nutr. 2010 Nov,92(5): 1060-70.

85 Liu X, Zhai T, Ma R, Luo C, Wang H, Liu L. Effects of uric acid-lowering therapy on the progression of chronic kidney disease: a systematic review and meta-analysis. Ren Fail. 2018 Nov;40(1):289-97. 